\title{
BUS CLAMPED PWM TECHNIQUE FOR THE SENSORLESS COMMUTATION OF BRUSHLESS DC MOTOR
}

\author{
Hithesh C N \\ M.Tech, Power Electronics \\ Dept. of Electrical and Electronics Engineering \\ BMS College of Engineering, Bengaluru, India
}

\begin{abstract}
The Brushless DC (BLDC) motor is a permanent magnet synchronous motor with trapezoidal back EMF waveform. The sensorless commutation of BLDC motor is the method of commutation of stator windings without using the rotor position sensors. The BLDC motor mainly used in variable speed applications. The motor speed is controlled by controlling the applied voltage and normally PWM switching technique is used to get variable voltage. In this paper a new type of pulse width modulation (PWM) switching technique is implemented for the control of three phase BLDC motor. In this PWM technique, the PWM signals are applied only to the high side switches of the inverter and low side switches signals are clamped to constant high voltage whenever a low side switch is be turned on. The bus clamped PWM will produce high torque in motor even at lower speed. The normal PWM technique and the bus clamped PWM technique are implemented on the dsPIC33CK microcontroller and the results are verified.
\end{abstract}

Keywords - Brushless DC (BLDC) motor, Sensorless Commutation, Pulse Width Modulation (PWM), Microcontroller.

\section{INTRODUCTION}

The permanent magnet synchronous motors are commonly used in high speed and high torque applications. "The motors trapezoidal back EMF waveform are known as Brushless DC (BLDC) motor". The rotor of the BLDC motor is a permanent magnet. The behaviour of the BLDC motor is similar to that of the conventional DC motor and they are used significantly in the constant torque applications." The rotor of the BLDC motor is a permanent magnet and the motor is rotated by the commutation of the stator windings". The commutation of the motor can be done using the information of the rotor position. The commutation of the BLDC motor by detecting rotor position using position sensors is known as sensored commutation technique. The commutation without using the position sensors is known as sesorless commutation technique.

\author{
L Venkatesha \\ Professor \\ Dept. of Electrical and Electronics Engineering \\ BMS College of Engineering, Bengaluru, India
}

In the sensorless commutation technique the motor rotor position is detected using the back EMF produced in the motor windings. There are many sensorless algorithms have been developed using the microcontrollers and digital filters. The sensorless commutation is implemented in this paper using new PWM technique called as bus clamped PWM technique. In the bus clamped PWM technique is implemented for the three phase BLDC motor using dsPIC33CK microcontroller. In this PWM technique the motor is commutation through a three-phase inverter. During the turn on time of the high side switches of the inverter are the energised using PWM pulses and during the turn on time of the low side switches, the switches are clamped to the higher voltage. Hence PWM technique is called as bus clamped PWM technique.

The bus clamped PWM technique will provide higher toque to the motor even at the lower speed. The hardware results of the bus clamped technique implemented for the BLDC motor are also explained in this paper.

\section{SENSORLESS CONTROL OF BLDC MOTOR}

The sensorless control of BLDC motor block diagram is shown in the figure 1 . The three phase BLDC motor is excited with the help of a three-phase inverter and it is powered using a DC bus voltage. The PWM signals are generated using the controller and applied to the inverter. Also to detect the rotor position of the motor using the back EMF generated in the motor.

There are many sensorless control methods have developed like microcomputer based[1], zero crossing detection from the back EMF[2], line to line voltage based[3], the rotor flux base[4] and virtual third harmonic based[5] algorithms. In this paper the sensolrless control algorithm is implemented based on back EMF detection using digital filter [6]. The main modification is the implementation of bus clamped PWM technique. 
International Journal of Engineering Applied Sciences and Technology, 2020

Vol. 5, Issue 3, ISSN No. 2455-2143, Pages 469-473

Published Online July 2020 in IJEAST (http://www.ijeast.com)

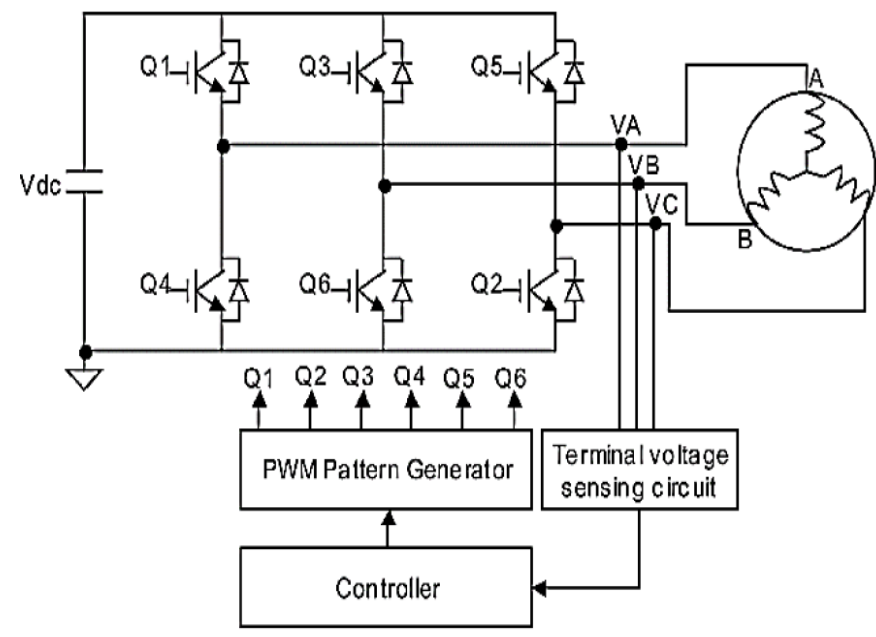

Fig. 1. Sensorless control of BLDC motor

The switches Q1 to Q6 are switched in the 120 degree electrical in the conduction mode and two switches conducting at a time. The speed of the motor is can varied by varying the applied voltage. The standard technique to get variable speed is by PWM based DC voltage to the motor.

\section{BUS CLAMPED PWM TECHNIQUE}

In the normal PWM switching technique both the high side switches (Q1 or Q3 or Q4) and the low side switches (Q2 or Q4 or Q6) will turned on and turned off at time.

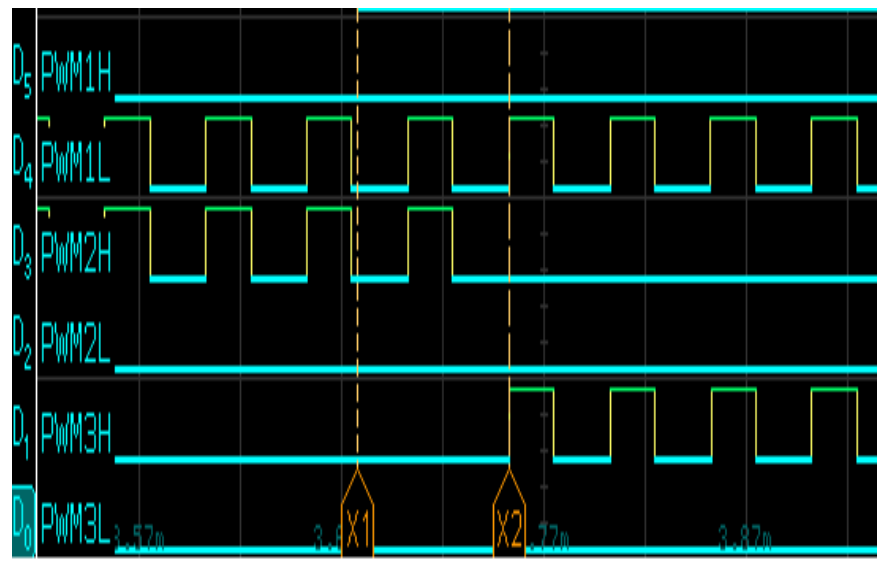

Fig. 2. Standard PWM signals applied to the motor

The standard PWM signals that are applied to the inverter to obtain the variable voltage are shown in the figure 2 . The PWM2H signal is applied to Q3 switch and PWM1L signal is applied to Q4. In this mode both low side switch and the high side switch will have the same conduction time. Due the same conduction and at very low speed the motor will need very small voltage. Hence the duty cycle applied will be small, correspondingly the conduction time will be less. The winding of the BLDC motor has significant inductance which causes the winding current to go to discontinuous mode of the conduction shown in the figure 3 .

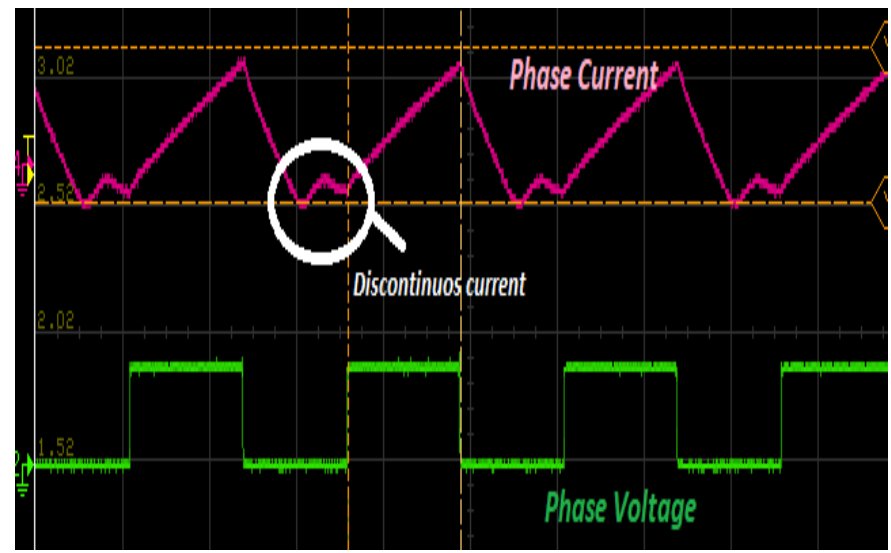

Fig. 3. Phase voltage and current of motor with standard PWM technique

The discontinuous current is due to the discharge of energy stored in the motor inductance during off time of the PWM signal. "The electromagnetic torque produced by the motor is directly proportional to the phase current of the motor". Due to the discontinuous current the magnitude of the electromagnetic torque produced becomes low. This would be the disadvantage for the high starting torque applications.

The bus clamped PWM technique is introduced to overcome the disadvantage of the discontinuous current at low speeds. In the bus clamped PWM switching technique the high side switches (Q1 or Q3 or Q4) will be turned on and off depending on the PWM duty cycle. But the low side switches (Q2 or Q4 or Q6) will be clamped the maximum voltage during their conduction time.

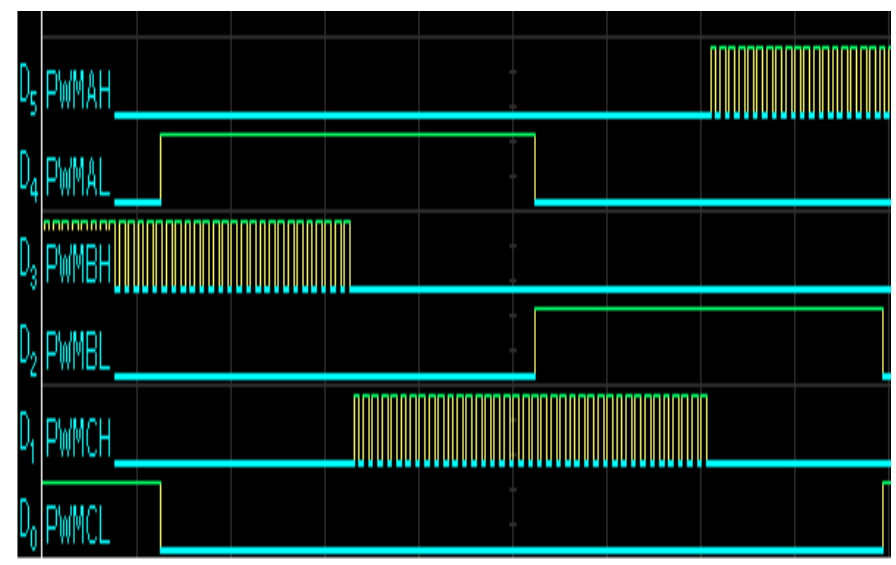

Fig. 4. Bus Clamped PWM signals applied to the motor 
The bus clamped PWM signals applied to the motor is shown in figure 3 . The low side switching signals are always turned in this PWM technique. Because of this the motor inductance will not have sufficient negative voltage to get discharge and to go into discontinuous conduction mode. The motor inductance energy discharge will be very slow, and magnitude of the motor will be high compared to the normal PWM technique. The motor phase voltage and current waveform is shown 5 with bus clamped PWM technique

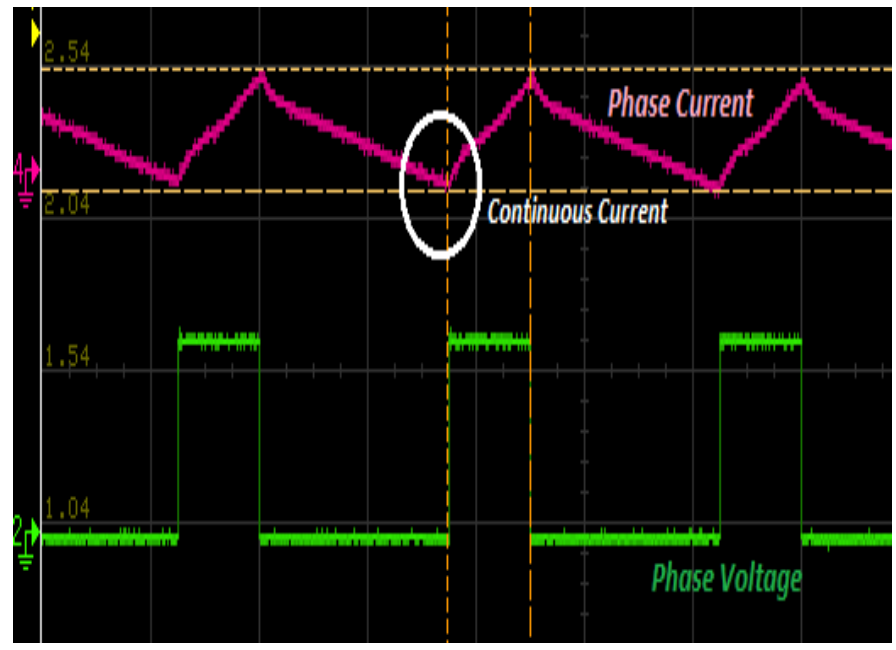

Fig. 5. Phase voltage and current of motor with bus clamped PWM technique

\section{HARDWARE IMPLEMETATION}

The bus clamped PWM is implemented on the hardware for Brushless DC motor with sensorless commutation algorithm using dcPIC33CK microcontroller. The motor parameters used for the hardware implementation are shown in table 1.

Table -1 Motor Specifications

\begin{tabular}{|c|c|}
\hline PARAMETER & VALUE \\
\hline Rated Voltage & $24 \mathrm{~V}$ \\
\hline Rated Current & $1 \mathrm{~A}$ \\
\hline Rated Power & $24 \mathrm{~W}$ \\
\hline Rated Speed & $3300 \mathrm{rpm}$ \\
\hline Number of Poles & 10 \\
\hline
\end{tabular}

The hardware setup for the implementation of the bus clamped PWM technique based sensorless control scheme is shown in the figure 6 . The DC power supply is used to power up the hardware and the motor. The MCLV-2 motor control development board with dsPIC33CK microcontroller is used develop bus clamped PWM signals and the sensorless algorithm. The computer is used write the algorithm and it is programmed to microcontroller using a programmer. The oscilloscope is used watch the signals.

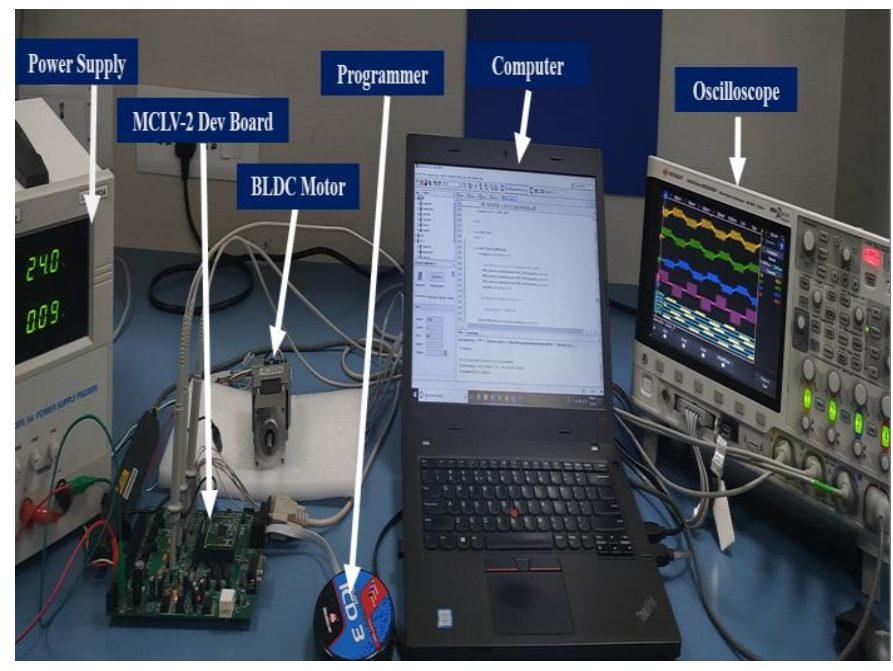

Fig. 6. Hardware test setup

\section{RESULTS}

The bus clamped PWM signals obtained from microcontroller for the inverter is shown in the figure 7 . During on time of the low side switch signals, they are clamped to bus voltage. The duty cycle of the high side switches of the inverter can be varied only for the to get the variable voltage.

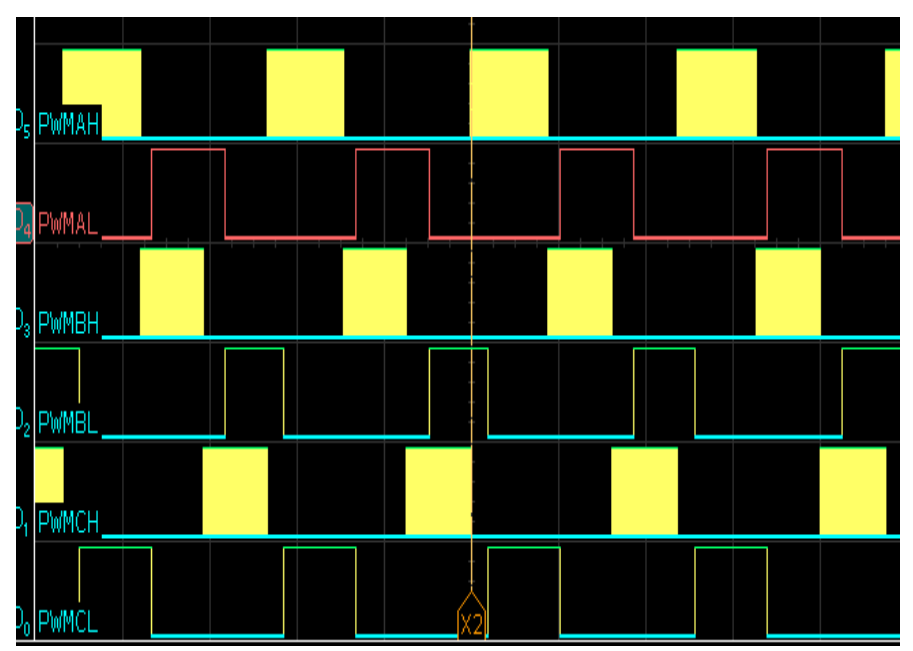

Fig. 7. Bus Clamped PWM signals 
International Journal of Engineering Applied Sciences and Technology, 2020

Vol. 5, Issue 3, ISSN No. 2455-2143, Pages 469-473

Published Online July 2020 in IJEAST (http://www.ijeast.com)

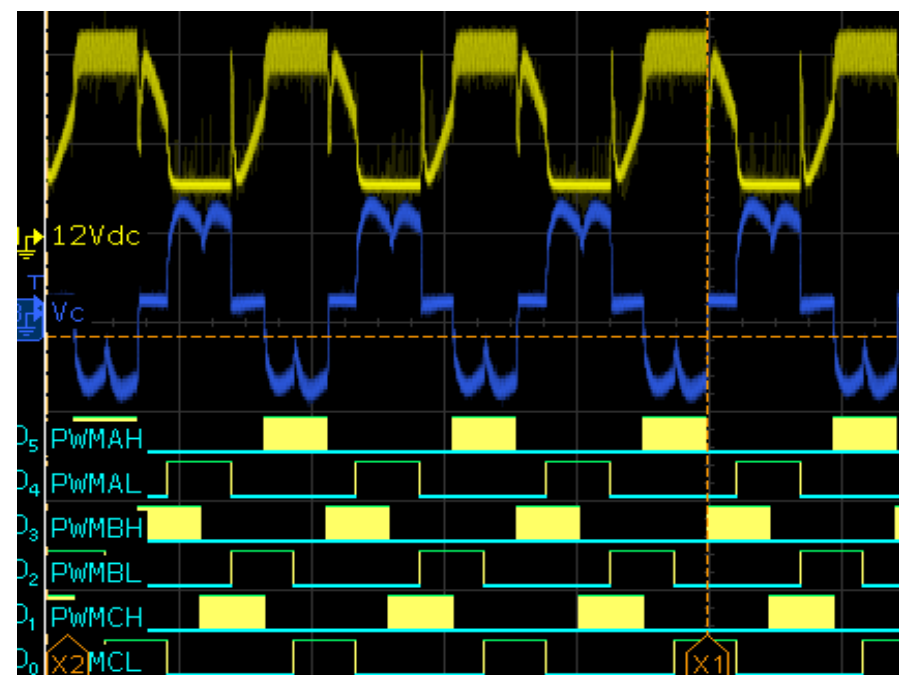

Fig. 8. Motor Phase voltage and phase current waveforms along with bus Clamped PWM signals

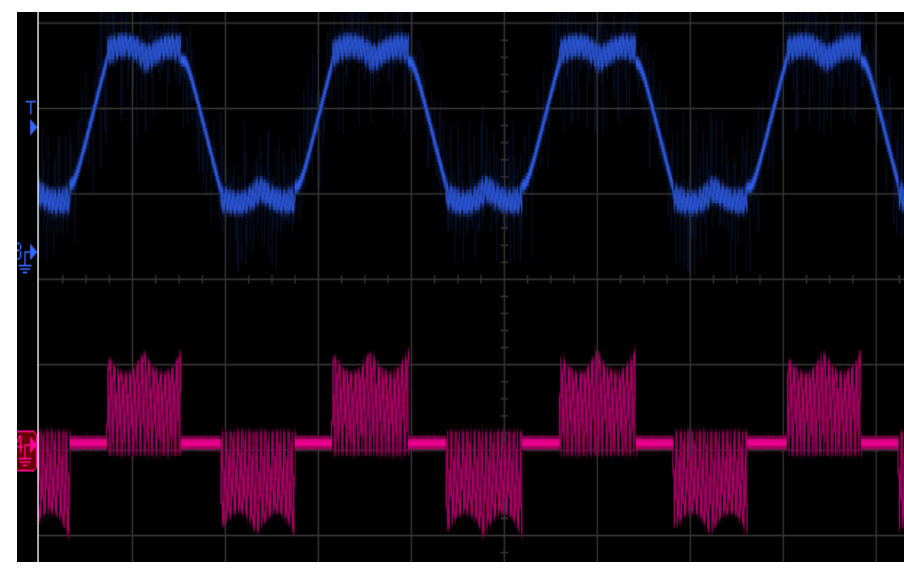

Fig. 9. Motor Phase voltage and phase current waveforms along with standard PWM signals

The BLDC motor phase voltage and phase current waveform captured at motor running at maximum speed is shown in the figure 8 . The phase current and phase voltage are measured at the one of the phases of three phase BLDC motor. The figure 8 also contains the bus clamped PWM signals applied to the motor at the same time. The motor phase voltage and current for the same motor using standard PWM technique is shown in the figure 9 at the same speed.

From the figures 8 and 9, the motor takes lesser current in case of standard PWM technique as compared to bus clamped PWM technique at the same speed. Also the current in the standard PWM technique is in discontinuous mode, hence the electromagnetic torque produced by the motor will be less compared to that with the torque produced by the motor using bus clamped PWM technique.

\section{CONCLUSION}

The new PWM technique known bus clamped PWM technique is developed for the sensorless control of the BLDC motor. The advantages of bus clamped PWM technique over the standard PWM technique are discussed. The bus clamped PWM technique will provide the higher electromagnetic torque to the motor at the lower speeds. This technique will be very helpful in the BLDC motor high torque applications. . In bus clamped PWM technique the motor will take lower voltage to produce higher electromagnetic torque when compared to standard PWM technique. The developed PWM technique is implemented and tested on the hardware.

\section{REFERENCE}

[1] Kenichi Iizuka, Hideo Uzuhashi, Minoru Kano, Tsunehiro Endo and Katsuo Mohri, (1985). Microcomputer Control for Sensorless Brushless Motor, IEEE Transactions on Industry Applications.

[2] P. Damodharan and Krishna Vasudevan, (2010). Sensorless Brushless DC Motor Drive Based on the ZeroCrossing Detection of Back Electromotive Force (EMF) From the Line Voltage Difference, IEEE transactions on Energy Conversions.

[3] Gang Liu, Chenjun Cui, Kun Wang, Bangcheng Han and Shiqiang Zheng, (2016). Sensorless Control for Highspeed Brushless DC Motor Based on the Line-to-line Back-EMF, IEEE transactions on Power Electronics.

[4] Shaohua Chen, Gang Liu and Lianqing Zhu, (2017). Sensorless Control Strategy of a $315 \mathrm{~kW}$ High-Speed BLDC Motor Based on a Speed-Independent Flux Linkage Function, IEEE transactions on Industrial Electronics.

[5] Xinda Song, Bangcheng Han, Shiqiang Zheng and Jiancheng Fang, (2018). High-precision Sensorless Drive for High-speed BLDC Motors based on the Virtual 3rd harmonic back-EMF, IEEE transactions on Power Electronics.

[6] Sachith D'Souza and Rudranna Nandihalli, (2019) Design \& Implementation of Sensorless BLDC Motor Drive with Digital Filters for BEMF using dsPIC33CK Microcontroller, International Research Journal of Engineering and Technology (IRJET), Volume: 06.

[7] Rajesh T S and Joseph K D, (2014). Sensorless Operation of Current Controlled BLDC Drive with Phase Lag Compensation, International Conference on Power, Signals, Controls and Computation (EPSCICON). 
[8] Nobuyuki Matsui and Masakane Shigyo, (1992). Brushless DC Motor Control without Position and Speed Sensors, IEEE transactions on Industry applications.

[9] P.Nagasekhar Reddy, (2013). Modeling and Analysis of PI Controller Based Speed Control of Brushless DC Motor Drive, International Journal Of Engineering Sciences \& Research Technology.

[10] R Krishan, (2001). Electric Motor Drives - Modelling, Analysis and Control, Prentice Hall, Inc,

[11] Chang-liangXia, (2012). Permanent Magnet Brushless DC Motor Drives And Controls, John Wiley \& Sons Singapore Pte. Ltd.,

[12] Santanu Mondal, Arunabha Mitra, Madhurima Chattopadhyay, (2015). Mathematical modeling and simulation of Brushless DC motor with ideal Back EMF for a precision speed control, IEEE International Conference on Electrical, Computer and Communication Technologies (ICECCT). 